\title{
De la presencialidad a la virtualidad. La educación pública en Bogotá en tiempos de pandemia*
}

\author{
[Artículos]
}

\author{
Lina Paola Martínez Nieto** \\ Ángela Valencia Leal ${ }^{* * *}$ \\ Angélica María Valencia Murillo ${ }^{* * * *}$ \\ César Omar Fernando Niño Nieto ${ }^{* * * * * *}$
}

Recibido: 24 de noviembre de 2020

Aprobado: 7 de diciembre de 2020

\begin{abstract}
* Este artículo se deriva de las actividades de la Red de Educomunicación y Memoria (REM). La REM nace como una apuesta educativa de cambio social, que fundamenta sus bases en el trabajo con la comunidad educativa a partir de la implementación de diversos proyectos que surgen al interior de algunas instituciones educativas distritales de Bogotá, que son liderados por docentes maestrantes y egresadas de la Maestría de Comunicación, Desarrollo y Cambio Social de la Universidad Santo Tomás y de la Maestría de Estudios Culturales de la Universidad Nacional.

** Red de Educomunicación y Memoria. Magíster en Comunicación, Desarrollo y Cambio Social. Docente de la Secretaría de Educación del Distrito - Colegio Villas del Progreso IED, localidad de Bosa. Correo electrónico:

Ipmartinez@educacionbogota.edu.co; ORCID: https://orcid.org/0000-0001-8305-5768

${ }^{* * *}$ Red de Educomunicación y Memoria. Licenciada en Pedagogía Reeducativa. Aspirante a magíster en Comunicación, Desarrollo y Cambio Social. Docente de la Secretaría de Educación del Distrito - Colegio Sotavento IED, localidad de Ciudad Bolívar. Correo electrónico: avalencial@educacionbogota.edu.co; ORCID:

https://orcid.org/0000-0001-6511-2829

**** Red de Educomunicación y Memoria. Magíster en Comunicación, Desarrollo y Cambio Social de la Universidad Santo Tomás. Docente de la Secretaría de Educación del Distrito - Colegio Veinte de Julio IED, localidad de San Cristóbal. Correo electrónico: amvalenciam@educacionbogota.edu.co; ORCID: https://orcid.org/00000003-0068-3887

***** Red de Educomunicación y Memoria. Especialista en gestión de procesos psicosociales. Aspirante a magíster en Estudios culturales de la Universidad Nacional. Docente de la Secretaria de Educación del Distrito - Colegio La Amistad IED, localidad de Kennedy. Correo electrónico: cfernando@educacionbogota.edu.co; ORCID: https://orcid.org/0000-0003-0493-1454
\end{abstract}




\section{Citar como:}

Red de Educomunicación y Memoria. (2021). De la presencialidad a la virtualidad. La educación pública en Bogotá en tiempos de pandemia. Análisis, 53(98). https://doi.org/10.15332/21459169.6308

\section{(c) (1) $(9)$}

\section{Resumen}

Este artículo es una posibilidad de acercarse a algunas alternativas de la educación pública en Bogotá en medio de la emergencia sanitaria que se establece en estos tiempos de pandemia, cuando el paso de la presencialidad a la virtualidad ha establecido diferentes formas de aprendizaje, pero también ha puesto en evidencia directrices políticas estatales y distritales. Surge del contexto en que el docente y del docenteorientador han reaccionado desde una mirada crítica y transformadora, al fomentar y enriquecer experiencias centradas en la memoria y la educomunicación, que abarcan el trabajo colectivo en las localidades de San Cristóbal, Bosa, Kennedy y Ciudad Bolívar. Tiene como fin rescatar el valor del trabajo con diferentes comunidades educativas y dejar como punto álgido de reflexión la labor del docente en medio de esta transformación social. Teniendo como referente el quehacer individual, surge una serie de propuestas educativas para dar alcance a los procesos pedagógicos integrales, que den respuesta a las necesidades de cada uno de los contextos de las instituciones educativas distritales.

Palabras clave: educomunicación, memoria, virtualidad, procesos pedagógicos. 


\section{From face-to-face to online learning. Public education in Bogotá in times of pandemic.}

\section{Abstract}

This article is a possibility to approach some alternatives of public education in Bogotá in the midst of the health emergency that is stated in these times of pandemic, when the transition from face-to-face to online learning has established different forms of learning, but has also revealed state and district policy guidelines. It arises from the context in which the teacher and the teacher-advisor have reacted from a critical and transformative overview, by fostering and enriching experiences centered on memory and educommunication, which encompass collective work in the localities of San Cristóbal, Bosa, Kennedy and Ciudad Bolívar. Its purpose is to rescue the value of working with different educational communities and to leave the work of the teacher in the midst of this social transformation as a point of reflection. Taking as reference the individual work, a series of educational proposals arise to give scope to the integral pedagogical processes, which respond to the needs of each of the contexts of the district educational institutions.

Keywords: Educommunication, memory, online learning, pedagogical processes.

\section{Da presença à virtualidade. Educação pública em Bogotá em tempos de pandemia}

\section{Resumo}

Este artigo é uma possibilidade de abordar algumas alternativas da educação pública em Bogotá em meio à emergência sanitária que se estabelece nestes tempos de pandemia, quando a transição da presencialidade para a virtualidade estabeleceu diferentes formas de aprendizagem, mas também destacou as diretrizes políticas estaduais e distritais. Decorre do contexto em que o professor e o professor- 
orientador reagiram de uma perspectiva crítica e transformadora, promovendo e enriquecendo experiências focadas na memória e na educomunicação, que incluem o trabalho coletivo nas cidades de San Cristóbal, Bosa, Kennedy e Ciudad Bolívar. Seu objetivo é resgatar o valor de trabalhar com diferentes comunidades educacionais e deixar como ponto alto de reflexão o trabalho do docente em meio a essa transformação social. Tendo como referência o trabalho individual, surge uma série de propostas educativas para dar abrangência aos processos pedagógicos integrais, que respondem às necessidades de cada um dos contextos das instituições de ensino distritais.

Palavras-chave: educomunicação, memória, virtualidade, processos pedagógicos.

\section{Introducción}

Por causa de la emergencia sanitaria y las particularidades en los gobiernos latinoamericanos, cada país, en diferentes momentos, determinó el cierre de las instituciones educativas en sus espacios físicos y estableció que el ejercicio cotidiano de aprendizaje en el salón de clase migrara a la virtualidad.

Cada país acomodó sus recursos para responder a su percepción de escuela como espacio de formación puramente académica. Esto es, según Freire (1970):

En vez de comunicarse, el educador hace comunicados y depósitos que los educandos, meras incidencias, reciben pacientemente, memorizan y repiten. Tal es la concepción "bancaria" de la educación, en que el único margen de acción que se ofrece a los educandos es el de recibir los depósitos, guardarlos y archivarlos. (1970, p. 52)

Desde esta visión, fortalecida por los gobiernos neoliberales, la decisión de cerrar las escuelas debía suplirse con otra estrategia de aprendizaje diferente a la presencialidad (guías, videos, blogs, programas radiales o de 
televisión pública, entre otras). La respuesta estatal se centró en solicitar a los docentes y directivos estrategias para la transmisión de conocimientos propios de un currículo determinado para cada grado o programa educativo.

Para el caso de Colombia, el Ministerio de Educación Nacional lanzó la estrategia Aprender en Casa, con la cual se brindaban tres herramientas: en primera instancia, desde el blog Red Académica, se diseñan cartillas para todos los grados de primera infancia, primaria, secundaria y media; en segundo lugar, se genera material académico y didáctico a modo de contenido televisivo y radial de transmisión diaria por canales y emisoras públicas; en tercer lugar, se crea contenido académico en redes sociales para dar respuestas a las temáticas que se consideran, desde su mirada, importantes en la escuela.

Las acciones evaluadas por el Gobierno Nacional colombiano como exitosas desde la percepción que se tiene de escuela como lugar para transmitir saberes específicos se desprende de la realidad al evidenciar las condiciones de pobreza, desigualdad y escasez de oportunidades en el país. Se evidenció la poca posibilidad de que muchos estudiantes accedan a estas propuestas. El papel del Gobierno se queda en la creación de estas estrategias y se delega a las regiones (sumidas en la carencia de recursos y en la corrupción) crear acciones que garanticen el acceso al derecho de la educación en el periodo de pandemia. Algunas secretarías de educación (entidades gubernamentales regionales) intentan dar respuesta a la crisis con dineros públicos o privados, brindando apoyos en bonos, equipos, planes temporales de internet, entre otras.

Este ejemplo refleja la inoperancia estatal en su papel de garante de derechos fundamentales; legisla y delega en tiempos de crisis, pero desconoce los contextos. En estas condiciones, cada institución educativa 
debe buscar opciones para minimizar la vulneración de derechos, fundamentalmente el de la educación. En este sentido, se convierte en casi la única responsable del cumplimiento del proceso educativo, a través de la promoción de estrategias como la búsqueda de apoyos individuales, donaciones o, incluso, el uso de recursos de los mismos maestros para sortear las diversas condiciones de inequidad y apoyar el proceso educativo de sus comunidades.

De igual forma, el surgimiento de la pandemia y la necesaria transformación y migración de la actividad educativa hacia lo virtual evidenció la inmadurez de los procesos de comunicación y conectividad en las comunidades educativas (escuela, familia, estudiantes, docentes), pues, a pesar de que el mundo lleva décadas experimentando el impacto de la globalización como proceso económico, político y cultural, y se ha inmerso en el uso de las tecnologías de la información y la comunicación, son innegables las múltiples brechas preexistentes y no atendidas desde la intervención estatal en Colombia (Delgado, 2003). Existen aún grandes inequidades en cuanto al acceso a los medios tecnológicos, a la alfabetización en el uso de las tecnologías y a la tenencia de recursos económicos suficientes para para afrontar la educación desde la casa.

Dicha situación plantea la necesidad de potencializar los procesos educomunicativos en la gestión pedagógica/escolar, entendiendo que la educación está sostenida necesariamente sobre un intercambio comunicativo entre actores. Todos los miembros de la comunidad educativa deben ser alfabetizados en el manejo y uso de las tecnologías para que se puedan transformar en emisores y no solo receptores de contenido educativo (enfoque instrumental anglosajón). También, y mucho más importante, se debe fortalecer la educación en cuanto a los lenguajes y medios por los cuales se realiza la comunicación, a través la generación de un sentido crítico respecto al contenido comunicativo, la 
preparación para el intercambio dialógico, el análisis de los contenidos comunicativos y la participación activa en un escenario escolar donde el conocimiento no se transmite sino que se construye (enfoque dialógico) (Barbas, 2012).

Esta educomunicación originaría procesos pedagógicos nutridos por la creación colectiva derivada del intercambio de ideas y significados, por la construcción de aprendizajes colaborativos y participativos y por el fortalecimiento de sentido crítico y de herramientas para la vida personal, familiar e, incluso, para la transformación social. De hecho, como se verá a continuación, en el contexto de la pandemia, se pueden destacar diversas iniciativas o apuestas educativas que nacieron desde el diálogo con las comunidades y enriquecidas por las experiencias académicas y profesionales de los docentes que se movilizaron desde la educomunicación. Esta se define de la siguiente manera:

[...] campo aplicado de intervención sociocultural, que se sitúa a medio camino entre lo interpretativo (el "ser") y lo normativo (el "deber ser"), y se concentra en la planificación de acciones y estrategias desde la relación transversal educación/comunicación, con apoyo o no de medios y tecnologías, y entendiendo ambos fenómenos como dimensiones inseparables de lo político. (Barranquero, 2010, p. 2)

Estas experiencias pedagógicas fundamentaron vínculos comunicacionales horizontales para la atención a diversas problemáticas sociales, pero también se orientaron a garantizar el derecho a la educación en medio de las brechas tecnológicas, agudizadas por este paso de la presencialidad a la virtualidad.

De esta forma, las apuestas desde la memoria, la escuela de padres, la inclusión y reflexiones sobre la labor del docente atravesarán el presente documento, que incluye proyectos individuales desarrollados en varias 
localidades de Bogotá (San Cristóbal, Bosa, Ciudad Bolívar y Kennedy). Se implementaron procesos pedagógicos colectivos en varias instituciones educativas distritales como ejercicios activos y de aprendizaje para la comunidad, que buscan convertirse en apuestas educomunicativas y de memoria para el presente y la posteridad.

\section{Trascender en los procesos de memoria}

Los tiempos y los lugares cumplen una función importante y necesaria cuando de educomunicación y memoria se quiere hablar, puesto que recrear y dialogar sobre historias que se relaten desde el propio ser y también desde el otro supone afrontar las memorias de un pasado que no se vivió, de un pasado que incluso no se ha comprendido o, más aún, de un pasado que en las percepciones de los jóvenes no existe. Se trata de un pasado que solo se ha recreado, quizás imaginado o sencillamente representado en sus mentes, que, aunque dispersas, piensan, confrontan, accionan y se pueden salvar del olvido.

De ahí que la educación en los tiempos de pandemia siga su rumbo en la virtualidad, de modo que fortalezca apuestas desde la innovación, como es el caso de la propuesta desarrollada en el Colegio Veinte de Julio IED, localidad de San Cristóbal, con el proyecto denominado "Colombia, cómo me dueles. No te quiero olvidar: entre ficción y realidad, memoria y literatura". Esta propuesta educomunicativa que inicia en el año $2017 \mathrm{y}$ ha seguido vigente hace un aporte fundamental al campo de la memoria histórica en la escuela, desde el área de humanidades, asignatura Lengua Castellana. Involucra jóvenes entre los 13 y 18 años de los grados noveno, décimo y once. En este espacio se reconoce la articulación existente entre los planes curriculares y los conocimientos sobre el conflicto armado en el país, y pone en marcha estrategias que movilizan el pensamiento crítico de los estudiantes y la interacción de estos con los temas asociados a la 
memoria histórica. Asimismo, vincula su relación con la literatura como denuncia social, de forma ficcional y real, con el fin de crear y confrontar personajes que han experimentado esta violencia estructural y sistemática (Galtung, 2004). Así,

[...] la memoria, como sostiene Maurice Halbwachs, siempre se refiere a una persona que recuerda algo y que, mediante el lenguaje, puede establecer con otros y otras una comunicación que permita dar cuenta de la construcción de ese pasado que recuerda. En este sentido el lenguaje juega un papel decisivo en la explicación de la memoria. (Blair, 2002, p. 24)

Asimismo, se reconoce el abordaje del conflicto armado en la escuela como un tema difícil de pensar, pero mucho más de implementar. Desde esta apuesta, se realizan varias acciones que dan alcance a este propósito y que pretenden dejar instaladas, no solo en la escuela, sino en los estudiantes, conciencias críticas en torno a lo que pasó y está pasando como sociedad.

De esta manera se establecen las causas, consecuencias, situaciones y condiciones que han hecho posible que el conflicto armado en el país se haya prolongado por tantos años. Con esto, se pretende formar a un ser pensante, en palabras de Huergo, que tenga "un acceso a la información a través del fomento de valores solidarios y democráticos y el hallazgo de nuevos vínculos de comunicación, para la transformación social” (1999, p. 67). Para esto, se busca trabajar en temas correspondientes con el contexto colombiano, de modo que se fomente en los estudiantes la lectura crítica e intertextual y se generen en ellos ideas de cambio social frente al conflicto armado colombiano y el reconocimiento de la construcción de la memoria colectiva que atraviesan los relatos de sus ancestros y semejantes.

Así, la virtualidad secunda estas acciones pedagógicas con el uso de la plataforma dispuesta por la Secretaría de Educación del Distrito, como 
Teams, o plataformas más populares como Zoom o Meet, en donde se establecen estos diálogos de saberes para la socialización. Estas actividades se complementan con las entrevistas audiovisuales que se elaboran desde casa, la visita a los diferentes museos de la memoria interactivos, las lecturas de libros y crónicas, y las nuevas propuestas comunicacionales que implican seguir trabajando en el proceso de aprendizaje de varios estudiantes. Sin embargo, esta situación se convierte en la brecha de desinterés de otros educandos, ya sea por falta de herramientas tecnológicas para acceder a estos espacios virtuales o la poca apropiación de procesos autónomos como estrategia para ser aprendices.

Cabe anotar que una de las transformaciones de la presencialidad a la virtualidad para encontrar una comunicación asertiva y de escucha activa consiste en el desarrollo de un plan de estudios acorde con la realidad que se vive en nuestros tiempos. Se integran los diferentes factores que entran en juego en las relaciones dialógicas horizontales, las cuales se establecen desde el saber previo de los jóvenes hasta la orientación teórica y vivencial que se brindan en los diferentes encuentros remotos. No se puede

desconocer ni el contexto, ni el sujeto histórico, social y cultural que revela las diversas apreciaciones con las que llega, aprende, apropia y vivifica sus saberes desde casa.

\section{Fortalecer relaciones en medio de la pandemia}

Estudiar en tiempos de pandemia ha generado una radical ampliación de los límites de la educación escolar, pues se fusiona con la educación de la familia y muestra consecuencias que pueden enmarcarse en dos vertientes.

Por un lado, en los padres han movilizado sentimientos o actitudes de identificación y empatía con los profesores, dada la toma de conciencia sobre la tenacidad del rol docente y la envergadura de la labor pedagógica. En los profesores, se ha facilitado el reconocimiento y respeto por la 
dificultad que implica para los padres hacer un adecuado acompañamiento académico, mientras se responde simultáneamente por actividades domésticas e incluso laborales (las familias de estudiantes de colegios públicos con frecuencia trabajan en el sector informal, más cercano a su espacio doméstico).

Por otro lado, esta nueva condición educativa ha visibilizado y perpetuado las relaciones de fuerza y las contradicciones presentes en la relación familia-escuela en tanto existen conflictos por la atribución de responsabilidades sobre la educación (Garreta, 2008), el manejo de un vínculo jerárquico, de desconfianza mutua, unidireccional y de comunicación caracterizada por la transmisión de información desde la escuela y hacia la familia, y de divergencias en las expectativas mutuas frente al proceso (Aznar, 1998; Bolívar, 2006; Fernández, 1992; Martínez, 2015; Rivera y Milicic, 2006).

Así, si en la educación escolar previa a la pandemia era pertinente el acercamiento entre la familia y la escuela, en medio de este nuevo contexto biosanitario mundial mucho más. Sin embargo, como toda coyuntura, etapa de crisis o momento de transición, el confinamiento ha generado resultados variados que pueden incidir de manera favorable o no sobre los procesos de formación de los estudiantes, específicamente en el fortalecimiento de habilidades para la vida y de las competencias académicas que se pretendan desarrollar. Por lo tanto, todas aquellas iniciativas dirigidas a movilizar o mantener una relación cooperativa y de apoyo mancomunado entre familia y escuela, donde se fortalezcan otros modos, plataformas y sentidos de comunicación entre ellas, cobran una importancia fundamental para garantizar una educación integral y de calidad que brinde a niños y jóvenes suficientes herramientas, experiencias y saberes que les permitan afrontan un futuro cambiante y cargado de demandas en todos los ámbitos (personal, social, político, etc.). 
En este contexto, también se incluye el proyecto de intervencióninvestigación "Escuela de padres y madres: experiencias de participación y comunicación escolar”, que se implementa desde el año 2012 en colegios públicos de Bogotá (Colegio San Bernardino IED, de 2012 a 2018, y Colegio Villas del Progreso, de 2019 a 2020, en la localidad de Bosa). Tiene el objetivo de transformar las dinámicas de relación familia-escuela, a través de la construcción de escenarios de aprendizaje caracterizados por la promoción de una comunicación directa y recíproca, respetuosa y de reconocimiento mutuo, donde se valoran los saberes particulares y se promueve el aprendizaje cooperativo y significativo.

Por ello, en esta iniciativa se ha trabajado un proceso sistemático de intervención e investigación sobre la problemática de la fragilidad en la relación familia-escuela y la baja participación familiar en los procesos escolares; así, se tomó la comunicación como un proceso social fundamental que moviliza la participación ciudadana y el cambio social. Se han consolidado espacios que amplían la posibilidad de escuchar la voz de quienes cotidianamente no son parte activa del espacio intramural de la escuela, como padres, madres o cuidadores, entendiendo la comunicación como derecho y como herramienta de transformación, puesto que "lo que pretenden los educomunicadores es el reconocimiento del valor estratégico de la lucha por la libertad de la palabra, como una utopía que se concreta en acciones efectivas en los distintos espacios educativos" (De Oliveira Soares, 2009, p. 195).

Entonces, teniendo en cuenta el contexto de pandemia y la propuesta distrital y nacional de dar continuidad a los procesos escolares en modalidad virtual, la Escuela de Padres y Madres construyó estrategias alternativas, distintas al encuentro presencial colectivo tradicional, para interactuar con otras modalidades mediaciones novedosas para darle continuidad y no desenfocar el objetivo de la empresa iniciada. Así, se 
pusieron en funcionamiento grupos de Whatsapp por cursos con los padres, que facilitó a un buen número de familias la adaptación a la nueva modalidad académica.

Dicha herramienta sirvió de puente de información y retroalimentación, pues desde allí se recibieron las percepciones, ideas y sugerencias de los padres y fueron llevadas a instancias de decisión respecto al proceso. Claramente, no hubo planificación previa y la propuesta estuvo sujeta al ensayo y error, pero, en medio de un contexto azaroso y de fuerte incertidumbre, fue una zona de seguridad que permitió brindar tranquilidad a las familias y confianza a la institución sobre la entrega oportuna de información respecto a la gestión escolar y las actividades pedagógicas.

Asimismo, como estrategia de prevención del conflicto y de promoción de armonía en las relaciones intrafamiliares, con los múltiples riesgos derivados de la cuarentena, se diseñaron juegos y actividades cortas para realizar en familia. Se transmitieron a través de estos grupos en piezas comunicativas tipo meme y de las cuales también se recibían las impresiones y reflexiones de los padres, lo que generaba conversaciones entre los padres y aprendizajes sobre los temas tratados (comunicación asertiva, afecto en las relaciones familiares, prevención de violencia intrafamiliar, uso del tiempo libre, entre otras temáticas prioritarias). Más adelante, con la inevitable ampliación de la cuarentena se realizaron encuentros virtuales sincrónicos con los padres, e incluso actividades para padres e hijos, donde se retornó a la esencia lúdica y dinámica de los encuentros tradicionales presenciales, pero esta vez a través de plataformas virtuales. A través de juegos y de actividades de intercambio entre los miembros de la familia, se construyeron reflexiones sobre temas pertinentes a la situación actual (riesgos de las redes y el internet, el rol de 
acompañamiento de la familia, el respeto y afecto en la relación, el lugar de la infancia y la juventud), motivando el autorreconocimiento como protagonista de estos escenarios.

No obstante, a pesar de estos resultados gratificantes y satisfactorios, simultáneamente a este proceso se agudizaron y se hicieron mucho más evidentes las situaciones de desigualdad social, económica y educativa de un grupo de familias que no contaban con los medios (dispositivos y conectividad) para dar continuidad tanto a las actividades académicas como a las actividades de apoyo como la Escuela de Padres y Madres. Aunque se implementaron algunas estrategias a través de la entrega de material escrito, fue difícil hacer seguimiento a su impacto y las familias dieron prioridad a la devolución del trabajo académico y no a otras propuestas. Lo mismo ocurrió cuando cambiaron súbitamente las condiciones socioeconómicas y de estabilidad laboral de muchas familias, lo que es una problemática endémica de las poblaciones vinculadas a nuestros colegios públicos y de la estructura misma del sistema educativo dadas las carencias habituales (falta de recursos logísticos, tecnológicos, cantidad profesores $v s$. estudiantes, etc.).

Con todo, es evidente resaltar que estrategias como la Escuela de Padres y Madres favorecen el fortalecimiento de la relación familia-escuela e impactan positivamente en el proceso de formación de los estudiantes, a través del fortalecimiento una comunicación horizontal, bidireccional, basada en el respeto mutuo de saberes y orientada a un objetivo común.

\section{El derecho a la educación inclusiva en la virtualidad}

La Unesco, en el año 2015, planteó como desafío para la educación con meta para el año 2030 hacer de la inclusión y la equidad la base de la calidad en la enseñanza. Invita, desde los postulados de los Derechos Humanos, a diseñar y aplicar políticas y programas inclusivos, teniendo en 
cuenta las diversidades de los educandos. El contexto latinoamericano es un espacio en el que confluyen todo tipo de desigualdades y exclusiones; por tal razón, pensar la educación para todos es una problemática que aumenta con gobiernos de pensamiento radical que proponen políticas públicas según sus intereses y creencias particulares. Se pide, entonces, al docente que imparta una educación inclusiva sin la debida capacitación ni los recursos que se requieren, dentro de territorios de pobreza y con una violencia legitimada por algunos sujetos u organizaciones que discriminan a quienes se consideran diferentes o diversos.

Observado desde un enfoque diferencial, las aulas deben ser espacios de integración, tolerancia y con una línea de acción pedagógica que reconozca a los estudiantes con discapacidad, diversidad sexual, multiculturalidad, víctimas del conflicto armado, en condiciones de precariedad socioeconómica y otras características que se evidencian en el quehacer docente. Debe ser una educación para todos, que se ajuste a necesidades particulares.

Algunas instituciones educativas de Bogotá han buscado, desde hace varios años, fortalecer sus habilidades y recursos para el acompañamiento de esta población estudiantil según sus particularidades; otros han iniciado el proceso con el Decreto 1421 de 2017 (atención educativa a la discapacidad). Sin embargo, es una realidad que en Colombia los procesos pedagógicos inclusivos aún son incipientes, en mayor parte por los imaginarios existentes alrededor de la diferencia.

En este proceso de acercamiento a una educación inclusiva, desde el año 2011, la Institución Educativa Sotavento de la localidad Ciudad Bolívar ha adelantado acciones pedagógicas integrales que favorecen una educación para las diferentes poblaciones desde la mirada de la educación social. Este enfoque invita a trascender los espacios educativos curriculares 
formales a un conjunto de experiencias relacionales dentro de un determinado contexto social e histórico, que da lugar a cambios importantes del Plan Educativo Institucional (PEI) y genera una cultura del diseño de Plan Individual de Ajustes Razonables (PIAR, herramienta para el diseño del proceso enseñanza de los estudiantes con discapacidad). Se piensa como una herramienta de alcance educativo que no se limita a los estudiantes en condición de discapacidad.

El inicio de la estrategia "Aprender en casa" exige repensar la educación y complementar la experiencia educativa de aula, apuntando a fortalecer lo planteado previamente, con recursos de la educomunicación y así evitar lo sucedido, como lo explica Kaplún (1998) al hablar del auge de esta modalidad virtual, como una estrategia de autoaprendizaje en la cual se instrumentaliza la comunicación a través de canales masivos para envío de información, y deja de lado los diálogos y las reflexiones pedagógicas.

Desafortunadamente esto sucedió con la creación de guías masivas, canales de YouTube, Classroom y otras formas de envío de material para que cada estudiante se empoderara de su proceso educativo. Esta ruptura del aula a la virtualidad dejó en ceros los avances en educación inclusiva, pues se estandarizaron las herramientas, pensando en la cobertura de contenidos, lo que dio paso a una educación virtual excluyente.

Además, en esta nueva realidad es habitual observar que predominan situaciones de conflicto, disfuncionalidad y vulneración de derechos al interior de la familia, fenómeno que ha llevado a que muchas de estas funciones que deben garantizarse en el hogar se transfieran a la escuela. El apoyo emocional se pierde en el día a día con las responsabilidades laborales y el estrés que trae la pobreza, el conflicto, las injusticias; en muchas ocasiones, incluso, se desencadenan eventos de maltrato de todo tipo dentro de los núcleos. 
Ante esta situación, la escuela se ha convertido en una instancia a la que se le atribuye la prevención de riesgos asociados a la salud y el bienestar, incluso como responsable de las denuncias por los casos de vulneración de derechos, en el marco de los principios legales de corresponsabilidad que establece la Constitución Política Nacional.

Desde esta visión, en la cual se ha despojado de sus responsabilidades a cientos de familias, la llegada de la pandemia y, con esta, de la educación virtual, acentúan las limitaciones de algunas madres, padres y otros acudientes en el ejercicio de sus funciones en relación con su labor educativa. Encontraron, dentro de sus condiciones de pobreza, que ya no se contaba con el apoyo alimenticio o de salud que se recibe de algunos colegios; recibieron a sus hijos e hijas, a quienes dejaban en la escuela para ir a trabajar, con la tarea de acompañar su cuidado todos los días, todo el día, mientras de manera simultánea se atendían los deberes cotidianos que no se pueden posponer.

Se puede decir que las familias que se han logrado involucrar en los programas educativos virtuales creados, ya sea por el Gobierno o por las instituciones educativas, cuentan con cierto nivel de estabilidad económica, afectiva y además con algún nivel de formación académica que les permite apoyar a sus hijos e hijas en el proceso. Esta disparidad evidencia nuevamente la vulneración al derecho a la educación inclusiva, pues termina limitándose a un sector favorecido de la población.

Individualizar la educación y reencontrar al docente como comunicador es la apuesta que nace en esta experiencia: asesorar a los maestros en este camino de escucha y creación conjunta, manteniendo una red de apoyo interna y externa que permitiera minimizar la deserción y evitar los riesgos, especialmente emocionales por la ruptura de la escuela presencial con la llegada de la obligatoriedad virtual. 
Las llamadas telefónicas, los mensajes por WhatsApp y los correos electrónicos se convirtieron en los medios para acercar a los individuos en diálogos personales, emotivos, de apoyo, con el propósito de transformar una educación de contenidos por una educación esperanzadora y de mutuo apoyo en tiempos de crisis.

\section{iA nosotros también nos tocó!}

El docente, como agente educativo y sujeto social, ha encontrado en su rol formador la tarea por vocación de ser y dar respuestas a los procesos pedagógicos que orienta a partir de los lineamientos estatales y lineamientos distritales. De esta manera, su labor en estos tiempos de virtualidad se empieza a repensar, al encontrarse en una diatriba; como ser humano debe debatir con sus propias condiciones personales y a la par con las profesionales, puesto que debe atender las necesidades cognitivas y socioemocionales que hoy en día presentan sus educandos.

Este apartado nace tras el diálogo transdisciplinar y confrontante con varios docentes de distintas instituciones públicas del distrito capital. Esta comunicación "pandémica" (como se le ha denominado en conversaciones informales a la sobreexposición al computador, tableta, celular, televisor) ha dejado que el mundo después de la puerta y la ventana exterior pierda las sensaciones y vivencias de presencialidad, sin tener la importancia y la relevancia de los momentos del "cara a cara" pues todo se vivencia a través de las pantallas.

Entonces, es preciso resaltar que las múltiples dificultades propias de la cotidianidad subsisten, los deseos más simples se mantienen junto con los sueños propios de cada ser que habita y coexiste en este intrincado sistema social. Sin embargo, ha cambiado la manera de satisfacerlos, resolverlos y afrontarlos, con lo cual se visibilizan las enormes diferencias que un sistema social tan desigual ofrece a unos y otros. 
La pandemia afectó tanto a los sectores de más bajos recursos como a aquellos que en tiempos de "normalidad" vivían cómodamente, lo cual expuso que, en condiciones excepcionales, todos termináramos sufriendo por igual fenómenos como el acceso a la escuela, la tenencia de espacios de esparcimiento, la anhelada privacidad, los soportes emocionales y la ayuda en momentos complicados que nunca se habían vivido.

En el entorno de los docentes toma relevancia la profunda inequidad que se padece, al observar cómo a quienes se acompaña cada día (estudiantes y familias) la realidad del sistema educativo y su poca preparación para atender situaciones de coyuntura como la pandemia les negó sistemáticamente una educación humana y sensata bajo la premisa capitalista del acceso a los recursos tecnológicos, que para burócratas y tecnócratas son básicos y elementales, pero que en la cruda realidad terminan siendo lujos. Se añade a esto una escalonada deserción escolar tanto de los estudiantes como de sus familias, quienes terminaron reconociendo la difícil labor de enseñar y aprender sin medios y sin suficientes recursos.

Para ejemplificar esta situación, se referencian algunos casos expuestos en dichas comunicaciones "pandémicas" como formas de catarsis de y para los docentes que a continuación aparecen como diálogos horizontales y abiertos a receptores que han padecido y padecen estas situaciones. Primer caso. Expresiones como las de Andrés (un estudiante que puede ser uno más en la lista de cualquier institución educativa distrital), quien en un diálogo telefónico con su profesor Miguel (un docente que puede ser uno más de los 33 ooo docentes del distrito capital) le dice: "Sencillamente no sigo profe", pues tiene que salir a buscar lo del sostenimiento básico y, mientras cuelga la llamada que le costó minutos y minutos al profesor receptor, le arranca un pedazo más del corazón. “iAcaso es justo!”, expresa 
el docente, mientras en un explosivo pero silencioso gesto el académico escucha con impotencia cómo su agente emisor se le va de sus manos, con sentimientos de no regreso, dejándole claro el mensaje y sin sintonía en el canal.

Un segundo caso. No es raro escuchar la voz del docente que expresa tras la bocina del celular: "No me quiero levantar hermano", y que en días normales era fuente de alegría y entusiasmo por los pasillos del colegio, cargando de "buenas vibras" a quienes lo observaban.

Tercer caso. Otro más dirá: “iEscasez de recursos!”. La que sería, en tiempos de presencialidad, la excusa del tesorero y el rector ahora pasa a ser un reclamo sustancial en las nuevas realidades.

Cuarto caso. Imaginar la pregunta detrás de la pantalla: “¿Cómo cumplir con lo que me piden?”. Cómplice del incumplimiento del encierro, murmura el coordinador, que se debate entre pedir más a sus profesores y el desespero que ve en sus rostros en la reunión de Zoom.

Quinto caso. “iMe cansé de pedir la renovación de equipos!”, grita el profesor de Sociales, que en muchas ocasiones enfrentó los reacios cuestionamientos de quienes lo veían como innecesario y estaban indispuestos ante cualquier innovación en las estrategias educativas.

Referenciar estos casos conlleva a hablar de esa desagradable desmoralización creciente de los profesores que se perpetúa al ver que con el paso de los días se agudizaban sus precarias condiciones laborales. Si bien no bastaba con perder a sus "hijos adoptivos" (término acuñado por varios docentes para referirse a los estudiantes), además se les suma la poca preparación institucional y la amplia carencia de recursos para poder transitar en el mundo del conocimiento virtual. Aunque asistan menos estudiantes, la planta docente se carga de reclamos de padres y exigencias 
de los planteles educativos y las disposiciones de las políticas estatales y distritales distantes de acciones pedagógicas viables.

Los profesores, como profesionales de la educación, también viven y sufren la pandemia, la tensión propia de cada día en que los límites entre el trabajo y la vida se hicieron más difusos, y el "horario" dejó de existir para convertirse en una serpiente que sutil los envuelve y asfixia. Qué decir del cambio en los modos de comunicación que reclamó victorioso cada espacio de sus vidas, tras la llegada abrupta de las nuevas tecnologías que imponen una comunicación mediada por pantallas y bocinas, si ya las paredes los hacen sentir acosados por todos los costados; hoy se confunde con ese modelo de comunicación pedagógica que golpea de frente y sin avisar.

Así vivimos ahora en los destiempos de la educación. Lo presentía Barbero (1996), ya no tenemos familia a partir del amasijo en que se transformó el lugar que de alguna manera llamamos aún hogar; dejamos de ser un ser para convertirnos en pixeles y muchas carnes. La expresión "solo sé que nada sé" supera cualquier tipo de realidad virtual o presencial en un mundo de tecnologías que de ser amigas se transformaron en inquisidores imperantes.

\section{Conclusiones}

El paso de la presencialidad a la virtualidad en el sector educativo distrital ha dejado pros y contras en medio de situaciones adversas y de esperanza, que llevan consigo la responsabilidad de mantener una comunicación abierta que, como dice Pasquali "es un proceso de doble vía, posible cuando entre los dos polos de la estructura relacional, rige una ley de bivalencia: todo transmisor puede ser receptor, todo receptor puede ser transmisor" (1963, p. 72). 
Sin embargo, en un análisis desalentador, las instituciones educativas públicas, representadas por sus docentes, docentes-orientadores y directivas, a pesar de sus propias vicisitudes y manifestaciones en medio de una comunicación "pandémica", se han convertido en formadores de hábitos, normas y valores; algunas familias dejan de lado este acompañamiento a sus hijos e hijas debido a las necesidades económicas que los motivan a salir de sus hogares en horarios extendidos para proveer los ingresos, que en ocasiones son insuficientes para dar cumplimiento a lo básico.

En esta misma línea, también está la poca o nula responsabilidad de varios agentes educativos (estudiantes y padres), quienes teniendo acceso a los medios de trabajo para acceder a los aprendizajes desde la virtualidad, decidieron dejar al azar su año escolar.

Asimismo este sostén continúa en los siguientes contextos: la escuela garantiza el alimento a partir de la entrega de bolsones o bonos; las brechas culturales, sociales y cognitivas se siguen ampliando en un sistema educativo estatal y distrital que privilegia el acceso a las herramientas tecnológicas de unos en detrimento del aprendizaje de otro.

Esta ruptura del aula a la virtualidad dejó en ceros los avances en educación inclusiva, pues se estandarizaron las herramientas, pensando en la cobertura de contenidos.

Se dio paso a una educación virtual excluyente que se ve desfavorecida a través de las plataformas, redes y medios de difusión de la información. Se dejó la comunicación escolar y pedagógica carente de lineamientos claros y concisos para acceder a una educación facilitadora de aprendizajes según las necesidades cognitivas y socioemocionales de varios educandos, con diagnósticos psicológicos y clínicos. 
Ahora bien, para no ser pesimistas ante este panorama, se encuentran como fortalezas la versión 2020 de la Escuela de Padres y Madres, que pretendió incidir, mediar o atenuar las consecuencias generadas por esta nueva modalidad educativa, especialmente por las descritas respecto a la relación padres-profesores o familia-escuela. En general, tanto padres como profesores reconocen que las estrategias implementadas apoyaron el proceso educativo escolar de los estudiantes y facilitaron procesos de intercambio comunicativo entre el colegio y la familia.

También se encuentra la posibilidad que exigió pensar a cada estudiante desde su diversidad, definida no solo desde una condición especial, sino desde su realidad de pobreza, violencia, crisis emocional y desmotivación escolar. Fue necesario invitar al docente a redefinir su rol como comunicador, motivarlo a la apertura de canales de comunicación donde fuera no solo el hablante, sino que escuchara al educando y a quien lo acompaña en un ejercicio empático de conocer y entender sus vivencias, favorecer el diálogo crítico para encontrar caminos que permitieran atender dificultades y potenciar la acción autónoma del aprendizaje a pesar de las limitaciones en los recursos.

Finalmente, están las apuestas a los procesos pedagógicos integrales que reivindican el papel de la memoria en nuestra sociedad y los pro que se ven reflejados en proyectos educomunicativos que vinculan las narrativas literarias al campo de conocimiento del conflicto armado de este país. Estos son necesarios teniendo en cuenta las diversas problemáticas de violencia que aquejan a Colombia en medio de la situación de emergencia sanitaria actual, en donde la indagación, el pensamiento crítico y la confrontación intertextual de los educandos juegan un papel determinante para la formación de ciudadanías participativas y activas. 


\section{Referencias}

Aznar, P. (1998). Interacción familia-escuela: Mediación educativa familiar en el aprendizaje escolar. En V. Llorent-Bedmar (coord.), Familia y educación: una perspectiva comparada (pp. 351-362). Universidad de Sevilla.

Barbas, A. (2012). Educomunicación: Desarrollo, enfoques y desafíos en un mundo interconectado. Foro de Educación, (14), 157-175.

Barranquero, A. (2010). Comunicación participativa y educación en medios: implicaciones del concepto de prealimentación (“feed-forward”) de Mario Kaplún [ponencia]. En Congreso Euro-Iberoamericano de Alfabetización Mediática y Culturas Digitales, Universidad de Sevilla y Universidad Autónoma de Barcelona, España.

Blair, E. (2002). Memoria y narrativa: la puesta del dolor en la escena pública. Estudios Políticos, (21), 9-28. https://revistas.udea.edu.co/index.php/estudiospoliticos/article/view/1413

Bolívar, A. (2006). Familia y escuela: dos mundos llamados a trabajar en común. Revista de educación, 339, 119-146.

Delgado, P. (2003). Repensar la edu-comunicación desde la globalización: alternativas educativas. Comunicar. Revista Científica de Comunicación y Educación, 20, 9094. https://orcid.org/0000-0002-4717-3406

De Oliveira Soares, I. (2009). Caminos de la educomunicación: utopías, confrontaciones, reconocimientos. Nómadas, 30, 194-207.

Fernández, M. (1992). Poder y participación en el sistema educativo. Sobre las contradicciones del sistema escolar en un contexto democrático. Paidós.

Freire, P. (1970). Pedagogía del oprimido. Tierra Nueva.

Garreta, J. (2008). La participación de la familia en la escuela pública. Las asociaciones de padres y madres del alumnado. CIDE; CEAPA.

Galtung, J. (2004). Violencia, guerra y su impacto. Sobre los efectos visibles e invisibles de la violencia. Polylog. Foro para filosofía intercultural 5. http://them.polylog.org/5/fgj-es.htm

Huergo, J. (1999). Cultura escolar, cultura mediática. Universidad Pedagógica Nacional. 
Kaplún, M. (1998). Una pedagogía de la comunicación. Ediciones de La Torre.

Barbero, J. M. (1996). Heredando el futuro. Pensar la educación desde la comunicación.

Nómadas, (5). http://nomadas.ucentral.edu.co/index.php/inicio/44-

comunicacion-educacion-una-relacion-estrategica-nomadas-5/681-heredando-elfuturo-pensar-la-educacion-desde-la-comunicacion

Martínez, L. P. (2016). Representaciones sobre la participación de los padres de familia en la escuela [tesis de maestría, Universidad Santo Tomás]. Repositorio USTA.

https://repository.usta.edu.co/bitstream/handle/11634/9887/Mart\%C3\%ADnezLi na2016.pdf? sequence $=1 \&$ isAllowed $=\mathrm{y}$

Pasquali, A. (1963). Comunicación y cultura de masas. Universidad Central de Venezuela.

Rivera, M. y Milicic, N. (2006). Alianza familia-escuela: percepciones, creencias, expectativas y aspiraciones de padres y profesores de enseñanza general básica. Psykhe, 15(1), 119-135. http://dx.doi.org/10.4067/S0718-22282006000100010 